Research Paper

\title{
Chemotherapeutic Response and Prognosis among Lung Cancer Patients with and without Depression
}

\author{
Jue Chen ${ }^{1,2^{*}}$, Weichun $\mathrm{Li}^{2 *}$, Lin Cui ${ }^{2}$, Yayun Qian ${ }^{1}$, Yaodong Zhu' ${ }^{1}$, Hao Gu${ }^{1}$, Gaoyang Chen ${ }^{2}$, Yi Shen ${ }^{3}$, \\ Yanqing Liu ${ }^{\boxplus}$ \\ 1. Institute of Traditional Chinese Medicine and Western Medicine, School of Medicine, Yangzhou University, Yangzhou, Jiangsu, China; \\ 2. The Second People's Hospital of Taizhou affiliated to Yangzhou University, Taizhou, Jiangsu, China \\ 3. Department of Epidemiology and Medical Statistics, Nantong University, Nantong, Jiangsu, China \\ *These authors contributed equally to this work \\ $\square$ Corresponding author: Yanqing Liu, Institute of Traditional Chinese Medicine and Western Medicine, School of Medicine, Yangzhou University, \\ Yangzhou, Jiangsu Province, 225000, China; e-mail: Liuyq@yzu.edu.cn
}

() 2015 Ivyspring International Publisher. Reproduction is permitted for personal, noncommercial use, provided that the article is in whole, unmodified, and properly cited. See http://ivyspring.com/terms for terms and conditions.

Received: 2014.12.04; Accepted: 2015.06.11; Published: 2015.09.15

\begin{abstract}
Purpose: The current study examined quality of life, progression of disease, and survival rate during chemotherapy in newly diagnosed non-small cell lung cancer (NSCLC) patients with depression $(n=48)$ and without depression $(n=78)$. Further, the study explored the hypothesis that the survival benefit resulted from the chemotherapy of docetaxel and cisplatin (the DC regimen).

Patients and Methods: In total, 126 patients with newly diagnosed NSCLC participated in a cross-sectional study of DC chemotherapy integrated with standard oncology care in depression and non-depression groups. The health-related quality of life (HR-QOL) was assessed using the quality of life questionnaire for Chinese cancer patients receiving chemobiotherapy (QLQ-CCC). Depression was self-rated using the Zung Self-Rating Depression Scale (Z-SDS). Both HR-QOL and Z-SDS were completed before the first and after the last cycle of chemotherapy. Association between depression and quality of life, treatment responses, adverse effects and survival rate was considered positive at the significance level of $p<0.05$. Pearson and Spearman correlation coefficient, t-test and other statistical analysis were performed using the SPSS software version 13.0 for Windows.

Results: In total, 126 lung cancer patients were evaluated, $38 \%$ had a diagnosis of depression. The presence of depression was associated with reduced quality of life, increased progression of disease, nausea and fatigue and reduced survival rate by nearly 90 days on follow-up. Therefore, depression significantly predicted worse survival $(P=0.009)$.In addition, the chemotherapy DC regimen did not appear to improve the quality of life in depressed patients (SDS 94.96 \pm 18.14 before chemotherapy vs. SDS $100.04 \pm 16.61$ after therapy, $P=0.155$ ). In a secondary analysis, there was a positive relationship between depression and nausea and fatigue but there was no significant difference in hematologic toxicities between the depression and non-depression groups.

Conclusion: Depression was associated with worse survival in patients with newly diagnosed NSCLC. Also, the chemotherapy DC regimen did not improve quality of life in depressed patients and the data do not support the hypothesis that treatment responses of NSCLC patients with depression mediated the observed survival benefit from the $\mathrm{DC}$ regimen. There were more cases of progressed disease in the depressed group. Findings suggest that NSCLC patients with depression are at increased risk for decline in HR-QOL and survival rate during chemotherapy than patients without depression.
\end{abstract}

Key words: lung cancer, chemotherapy 


\section{Introduction}

Lung cancer is a widespread deadly disease with approximately 1.4 million deaths globally each year $[1,2]$. In China, lung cancer mortality increased by $464.84 \%$ in the past three decades, presenting a major public health issue [3]. Non-small cell lung cancer (NSCLC) accounts for about $80 \%$ of lung cancer cases, and most patients are diagnosed at inoperable advanced stages [4, 5]. As a result, systemic chemotherapy continues to be the mainstay of treatment to improve the survival and quality of life of patients [6]. Docetaxel and cisplatin (DC) are two anti-cancer agents without overlapping toxicity profiles, and their combination has been established as an active and well-tolerated regimen for NSCLC [7-10]. However, like many other regimens, the DC regimen only shows a $<50 \%$ response rate and limited survival benefit, which depend on patients' health status.

Symptoms of depression and anxiety have been identified in patients with cancer at a frequency of $12-24 \%$, which is significantly higher than patients with stroke, diabetes, and cardiovascular disease [11, 12]. In particular for lung cancer, it has been suggested that over $30 \%$ patients encounter a risk of depression development [13]. As such, several physical signs and symptoms are often observed in patients with lung cancer, including coughing, wheezing, weight loss, insomnia, fatigue, and chest pain [14]. These clinical symptoms can disturb quality of life and cause depressive disorder. Previous studies have suggested a certain association of depression with increased mortality among lung cancer patients [15-21]. However, studies are scarce that explore the potential mechanisms of reduced survival among depressed patients. There is a suggestion that the quality of life may be a key intermediary [22, 23]. Because of decreased quality of life and poor health status, it is possible lung cancer patients with depression choose not to initiate or continue treatments [24]. However, it is unclear whether patients' psychosocial factors are really associated with therapeutic response and survival in chemotherapy.

The purpose of the present study is to evaluate the association of depression with quality of life, therapeutic response, adverse effects, and prognosis in NSCLC patients with DC regimen chemotherapy. We explored possible mechanisms responsible for worse outcomes among depressed patients by determining the effects of patients' psychosocial factors.

\section{Materials and Methods}

\section{Patient eligibility}

Consecutive patients with newly diagnosed NSCLC at the Outpatient Oncology Clinic of The
Second People's Hospital of Taizhou City were assessed and screened for eligibility to enter the study (March 2010-March 2012). Subjects were included in the study if they met all of the following criteria: 1) 18 years of age or older; 2) histologically or cytologically confirmed NSCLC; 3) clinical stage IIIB or IV who were candidates for chemotherapy; 4) performance status (PS) of between 0 and 2, according to the Eastern Cooperative Oncology Group (ECOG) criteria; 5) cellular injury score (CIS) of between 0 and 2; 6) ability to provide written consent; 7) ability to participate in an interview or complete questionnaires; 8) absence of cognitive impairment; 9) absence of brain metastases, as confirmed by CT or MRI; 10) absence of uncontrolled comorbidities and acute/chronic complications; 11) absence of previous treatment for depression.

This study was cross-sectional and approved by the local institutional review board (IRB). All patients were requested to sign the informed consent form and provided details about the assessment procedure (Figure 1).

\section{Instruments}

\section{Health-related quality of life}

Health-related quality of life (HR-QOL) was assessed using the quality of life questionnaire for Chinese cancer patients receiving chemobiotherapy (QLQ-CCC) [25]. QLQ-CCC is comprehensive instrument widely used in China to measure health-related quality of life of cancer patients. The questionnaire consists of 35 items covering 5 different aspects of cancer patients, including disease/treatment-specific physical (9 items), non-specific physical (7 items), psychologi$\mathrm{cal} / \mathrm{spiritual}$ (5 items), social (5 items), and general health (9 items) aspects. This instrument has been validated through its application in several studies [26-29], showing adequate levels of reliability.

\section{Self-Rating Depression Scale}

The depression was self-measured among patients using the 20-item module of Zung Self-Rating Depression Scale (Z-SDS) [30, 31]. Subjects rate each item according to their feeling during the preceding week using a 4-point scale in which 4 represents the most unfavorable response. The sum of the 20 items, after correcting for the 10 items that are reverse-scored, produces a raw score that is converted into a self-rating depression score (termed as the "SDS" index). As per previous studies, the Z-SDS instrument has been established as a valid screening tool for the oncology population $[32,33]$.

All patients were requested to completed HR-QOL and SDS assessments before the first chem- 
otherapy cycle and after the last cycle. In the case of uneducated patients, two nurses were trained to collect the data by interviewing them and their relatives. Patients received any psychological treatment throughout the study would be excluded.

\section{Chemotherapy}

All patients were placed in the baseline investigation prior to chemotherapy which includes medical history, physical examination, biochemical workup, blood count, and thorax and abdomen computer tomography (CT) scan etc. The treatment plan was previously described with several modifications [8]. In brief, docetaxel was infused intravenously (i. v.) at 40 $\mathrm{mg} / \mathrm{m}^{2}$ for $1 \mathrm{~h}$, then cisplatin at $25 \mathrm{mg} / \mathrm{m}^{2}$ for $30 \mathrm{~min}$. For each cycle, docetaxel was given on days 1 and 15, and cisplatin on days 1 to 3 . Premedication of dexamethasone (8 $\mathrm{mg}$ i. v.) and fomotidine $(20 \mathrm{mg}$, i. v.) was provided prior to docetaxel and standard hydration was given with cisplatin. All patients received 5-HT3 antagonis and proton pump inhibitor (PPI) for antiemetic therapy. Treatment cycle was repeated every 4 weeks to a maximum of 6 cycles unless confirmed disease progression or intolerable side effects. For patients with earlier progression, second line regimens were allowed to administrate.

\section{Treatment response and follow-up evaluation}

Therapeutic responses were evaluated after three and six treatment cycles according to the Response Evaluation Criteria In Solid Tumors (RECIST), and classified as complete, partial, stable disease, and progressive disease [34]. Adverse effects were evaluated according to the National Cancer Institute-Common Toxicity Criteria, version 2.0, (NCI-CTC2), and graded as 0-V levels [35]. Blood counts were performed weekly, and other assessments were repeated every 3 weeks. All patients were monitored for 4 weeks after their last treatment cycle to detect any late adverse effects and then followed up biweekly until death. The Eastern Cooperative Oncology Group (ECOG) scale was employed to assess patients' performance status. Progression free survival was defined as the time from the first chemotherapy infusion to the first objective evidence of tumor progression. Overall survival (OS) was calculated as the time from the date of rolling to death due to any cause.

\section{Statistical analysis}

The measured values of self-rated depression scale before chemotherapy were dichotomized using a Z-SDS score of 50 as the cutoff. Therefore, patients were divided into two groups (depression and non-depression). Descriptive statistics and frequency distributions were generated from patients' demographics and disease-related characteristics. The QOL and SDS before and after chemotherapy were analyzed using independent $t$ test. Comparisons between depression and non-depression groups were performed using the Mann-Whit $U$ test for continuous variables according to normal distribution and $X^{2}$ for categorical variables. Pearson and Spearman correlation coefficient was used to determine the relationship between depression score and demographics, clinical characteristics, and treatment response. Survival analysis was performed using Kaplan-Meier estimate [36]. $P$ values less than 0.05 were considered to be significant. All analysis was performed with SPSS software version 13.0 for Windows (SPSS, Chicago, IL).

\section{Results}

A total of 186 NSCLC patients from the outpatient clinic were approached, of whom 156 patients were found to be eligible for enrollment in the study. Thirty patients were excluded due to not meeting the inclusion criteria (Figure 1). One hundred twenty-six patients returned the questionnaires for depression self-rating before chemotherapy. Seventy-three were male. The mean age of these patients was 60.7 years, and $50 \%$ of them were 60 years or older. Most participants $(95.2 \%)$ were married, and $73 \%$ had over 6 years of education. During the study entry period, only $28 \%$ were employed and $27.8 \%$ were fully insured for healthcare liability. There were $54.8 \%$ squamous and $45.2 \%$ adeno carcinomas, and all at advanced stages $(36.5 \%$ at stage IIIB and $63.5 \%$ at stage IV). Most cases had Eastern Cooperative Oncology Group-performance status (ECOG-PS) 1 (62.7\%) and Charlson index score 0-1 (78.5\%) (Table $1)$.

\section{SDS and HR-QOL scores}

Before chemotherapy, a baseline prevalence of depression of $38.1 \%(\mathrm{~N}=48$, SDS: $62.98 \pm 9.02)$ versus non-depression of $61.9 \%$ ( $\mathrm{N}=78$, SDS: $45.28 \pm 7.27$ ) was established among NSCLC patients according to Z-SDS evaluation. Table 1 presents the basic characteristics of patients with and without depression, showing that depression was not significantly related to gender, age, marital status, education, occupation, healthcare liability, carcinoma type, disease stage, ECOG-PS, and Charlson index score. In contrast, HR-QOL, particularly in physical, psychological, social, and general health scales, was significantly different between depression (total score: $94.96 \pm 18.14$ ) and non-depression (total score 113.58 \pm 14.64 ) groups $(P<0.01$, Table 2$)$. 


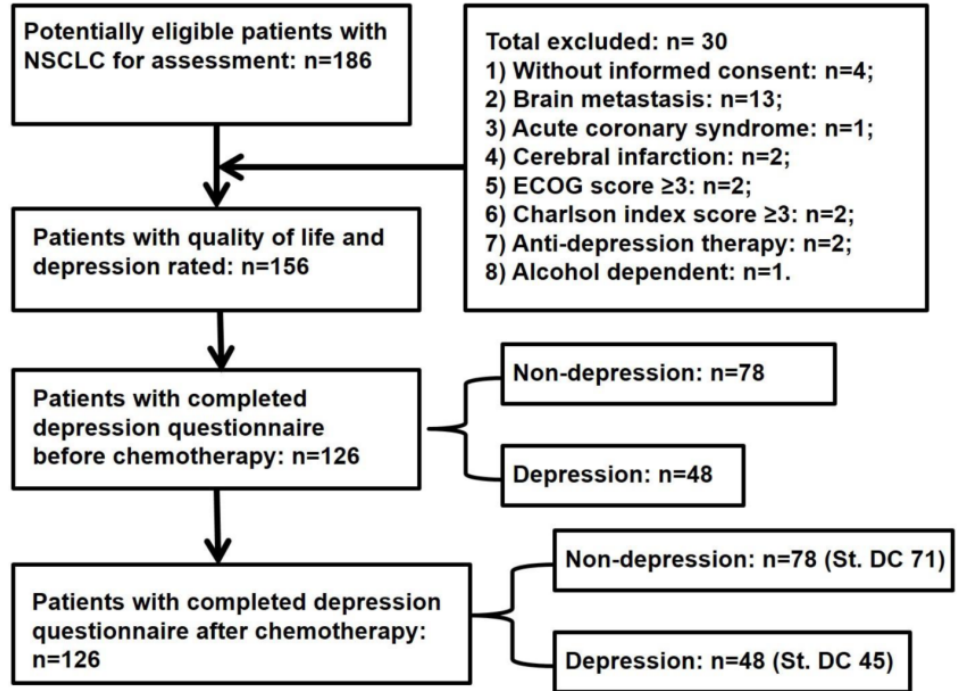

Figure 1. Flow diagram of study procedure for lung cancer patients. NSCLC, non-small cell lung cancer; ECOG, Eastern Cooperative Oncology Group; St. DC, standard docetaxel and cisplatin therapy.

Table 1. Demographic and clinical characteristics of lung cancer patients

\begin{tabular}{|c|c|c|c|c|c|}
\hline Characteristics, n (\%) & & All $(n=126)$ & Depression $(n=48)$ & Non-depression $(n=78)$ & $P$ \\
\hline \multirow[t]{2}{*}{ Gender } & Male & $73(57.9 \%)$ & $30(62.5 \%)$ & $43(55.1 \%)$ & 0.417 \\
\hline & Female & $53(42.1 \%)$ & $18(37.5 \%)$ & $35(44.9 \%)$ & \\
\hline \multirow[t]{4}{*}{ Age } & $19-38$ & $3(2.4 \%)$ & $2(4.2 \%)$ & $1(1.3 \%)$ & 0.145 \\
\hline & $39-58$ & $46(36.5 \%)$ & $19(39.6 \%)$ & $27(34.6 \%)$ & \\
\hline & $59-68$ & $52(41.3 \%)$ & $21(43.8 \%)$ & $31(39.7 \%)$ & \\
\hline & $69-79$ & $25(19.8 \%)$ & $6(12.5 \%)$ & $19(24.4 \%)$ & \\
\hline \multirow{2}{*}{$\begin{array}{l}\text { Marital } \\
\text { status }\end{array}$} & Married & $120(95.2 \%)$ & $46(95.8 \%)$ & $74(94.9 \%)$ & 0.806 \\
\hline & Not married & $6(4.8 \%)$ & $2(4.2 \%)$ & $4(5.1 \%)$ & \\
\hline \multirow[t]{4}{*}{ Education, years } & $\leq 5$ & $34(27 \%)$ & $12(25 \%)$ & $22(28.2 \%)$ & 0.433 \\
\hline & $6-8$ & $32(25.4 \%)$ & $10(20.8 \%)$ & $22(28.2 \%)$ & \\
\hline & $9-11$ & $35(27.8 \%)$ & $16(33.3 \%)$ & $19(24.4 \%)$ & \\
\hline & $\geq 12$ & $35(27.8 \%)$ & $10(20.8 \%)$ & $15(19.2 \%)$ & \\
\hline \multirow[t]{4}{*}{ Occupation } & Employed & $28(22.2 \%)$ & $11(22.9 \%)$ & $17(21.8 \%)$ & 0.617 \\
\hline & unemployed & $32(25.4 \%)$ & $9(18.8 \%)$ & $23(29.5 \%)$ & \\
\hline & Retired & $40(31.7 \%)$ & $18(37.5 \%)$ & $22(28.2 \%)$ & \\
\hline & Others & $26(20.6 \%)$ & $10(20.8 \%)$ & $16(20.5 \%)$ & \\
\hline \multirow[t]{3}{*}{ Healthcare liability } & Self-financed & $17(13.5 \%)$ & $4(8.3 \%)$ & $13(16.7 \%)$ & 0.367 \\
\hline & Half-Insurance & $75(59.5 \%)$ & $29(60.4 \%)$ & $46(59 \%)$ & \\
\hline & Full-insurance & $35(27.8 \%)$ & $15(31.3 \%)$ & $20(25.6 \%)$ & \\
\hline \multirow[t]{2}{*}{ Carcinoma type } & Squamous & $69(54.8 \%)$ & $22(45.8 \%)$ & $47(60.3 \%)$ & 0.116 \\
\hline & Adeno & $57(45.2 \%)$ & $26(54.2 \%)$ & $31(39.7 \%)$ & \\
\hline \multirow[t]{2}{*}{ Disease stage } & IIIB & $46(36.5 \%)$ & $17(35.4 \%)$ & $29(37.2 \%)$ & 0.842 \\
\hline & IV & $80(63.5 \%)$ & $31(64.6 \%)$ & $49(62.8 \%)$ & \\
\hline \multirow[t]{3}{*}{ ECOG-PS* } & 0 & $17(13.5 \%)$ & $8(16.7 \%)$ & $9(11.5 \%)$ & 0.763 \\
\hline & 1 & $79(62.7 \%)$ & $28(58.3 \%)$ & $51(65.4 \%)$ & \\
\hline & 2 & $30(23.8 \%)$ & $12(25 \%)$ & $18(23.1 \%)$ & \\
\hline \multirow[t]{2}{*}{ Charlson index score } & $0-1$ & $99(78.5 \%)$ & $41(85.4 \%)$ & $58(74.4 \%)$ & 0.390 \\
\hline & 2 & $27(21.4 \%)$ & $7(14.6 \%)$ & $20(25.6 \%)$ & \\
\hline
\end{tabular}

*ECOG-PS, Eastern Cooperative Oncology Group-performance status

After chemotherapy, no significant changes in depression scores were observed in either depression (SDS: $58.23 \pm 9.16$ vs. $62.98 \pm 9.02, P=0.091$ ) or non-depression (SDS: $44.37 \pm 7.75$ vs. $45.28 \pm 7.27$, $P=0.373$ ) groups (Figure 2). However, the total QOL score was significantly improved in the non-depression group $(123.17 \pm 13.38$ vs. $113.58 \pm$ $14.64, \mathrm{P}<0.01)$, which was reflected by the statistical increase of each sub-score (physical, psychological, social, and general health, $P=0.001-0.032)$. In contrast, no much change except the physical score was observed in the depression group (total scores $100.04 \pm 16.61$ vs. $94.96 \pm 18.14, P=0.155)$. In addition, a negative correlation between SDS and HR-QOL scores was noted before and after chemotherapy (Figure 3). 
Table 2. Quality of life scores for patients with and without depression

\begin{tabular}{lclll}
\hline Treatment & Variables & $\begin{array}{l}\text { Depression } \\
\text { (n=48) }\end{array}$ & $\begin{array}{l}\text { Non-depression } \\
\text { (n=78) }\end{array}$ & \\
\hline Before chem- & Total score & $94.96 \pm 18.14$ & $113.58 \pm 14.64$ & $<0.01$ \\
otherapy & $\quad$ Physical & $45.19 \pm 11.77$ & $57.41 \pm 9.95$ & $<0.01$ \\
& $\quad$ Psychological & $14.54 \pm 4.64$ & $16.56 \pm 3.97$ & $<0.05$ \\
& Social & $14.45 \pm 3.41$ & $16.38 \pm 3.22$ & $<0.05$ \\
& General health & $20.77 \pm 6.34$ & $23.22 \pm 5.17$ & $<0.05$ \\
After chemo- & Total score & $100.04 \pm 16.61$ & $123.17 \pm 13.38$ & $<0.01$ \\
therapy & Physical & $52.02 \pm 11.57^{*}$ & $60.95 \pm 9.68^{*}$ & $<0.01$ \\
& $\quad$ Psychological & $13.96 \pm 3.06$ & $17.79 \pm 3.05^{*}$ & $<0.01$ \\
& Social & $13.29 \pm 2.75$ & $17.74 \pm 3.17^{*}$ & $<0.01$ \\
& General health & $20.77 \pm 7.72$ & $26.83 \pm 7.32^{*}$ & $<0.01$
\end{tabular}

* After chemotherapy, scores for all four factors were improved in the

non-depression group, but only physical score was improved in the depression group.

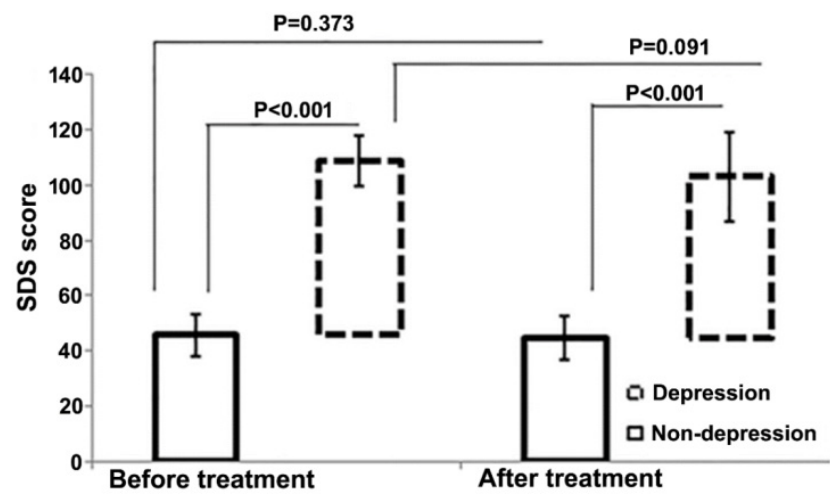

Figure 2. SDS score of patients with and without depression before and after treatment. The bars represent standard deviations.

\section{Treatment responses}

Both depression and non-depression groups had one case of complete response. Partial response was found for $33.3 \%$ of patients with depression, and $43.6 \%$ of patients without depression, respectively $(P<0.05)$. There is no significant difference in stable disease between two groups, but the depression group showed more cases of progressive disease than the non-depression group $(37.5 \%$ vs. $30.8 \%, \mathrm{P}<0.05)$ (Table 3).

\section{Adverse effects}

Leucopenia occurred in over $70 \%$ patients, but no association with depression was found in any NCI-CTC grades. In the depression group, 28 (58.3\%) patients developed thrombocytopenia in comparison with $37(47.4 \%)$ in the non-depression group. However, $40(51.3 \%)$ patients without depression developed anemia, but only $18(37.8 \%)$ patients with depression had this symptom. Overall, no significant difference of hematological toxicity exists between the depressed and non-depressed patients (Table 4).
Table 3. Treatment response in patients with and without depression

\begin{tabular}{lll}
\hline Response & Depression $(\mathbf{n}=\mathbf{4 8})$ & Non-depression $(\mathbf{n}=\mathbf{7 8})$ \\
\hline Complete response & $1(2.1 \%)$ & $1(1.3 \%)$ \\
Partial response & $16(33.3 \%)$ & $34(43.6 \%)$ \\
Stable disease & $13(27.1 \%)$ & $19(24.4 \%)$ \\
Progressive disease & $18(37.5 \%)$ & $24(30.8 \%)$ \\
\hline
\end{tabular}
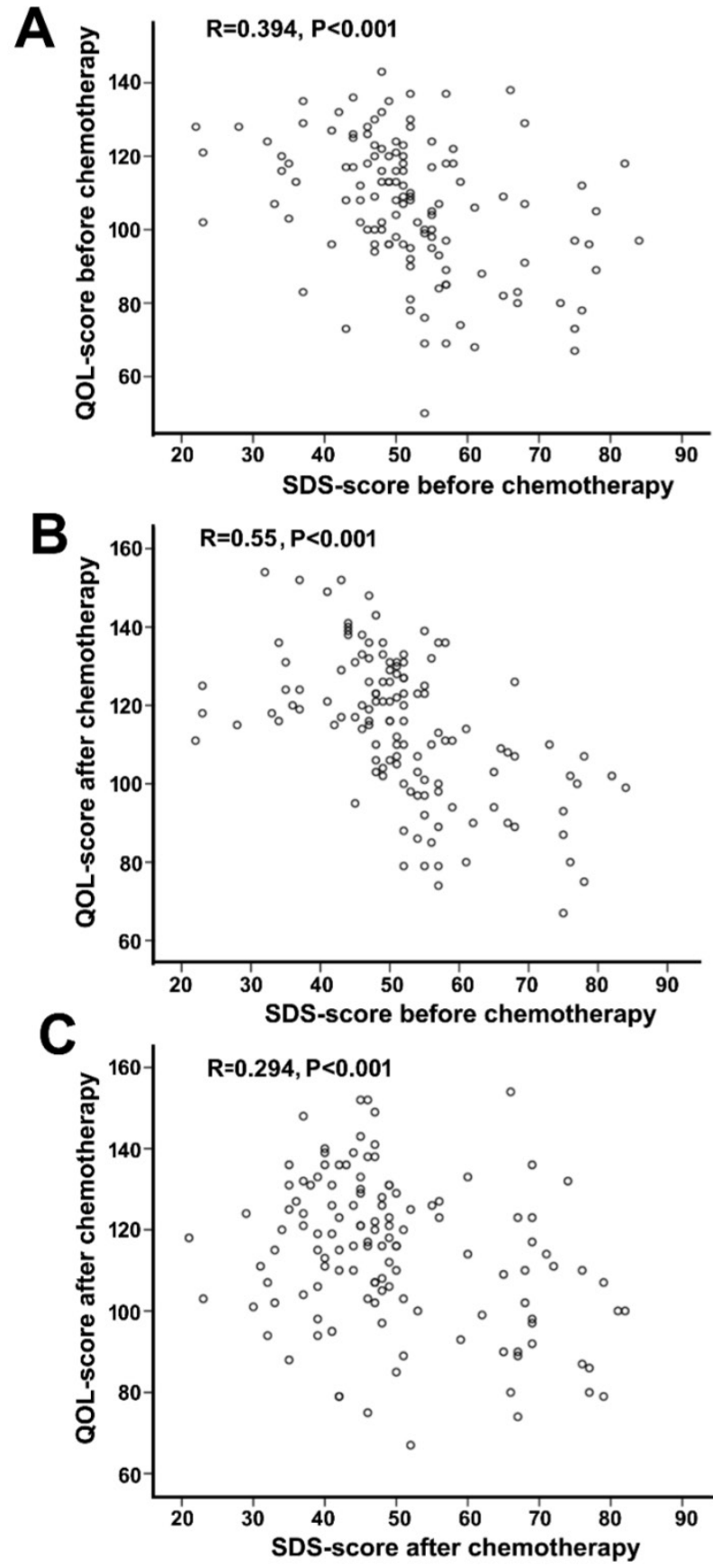

Figure 3. Correlation analysis between SDS score and QOL-CCC score in all patients. A,SDS-score before chemotherapy and QOL-CCC-score before chemotherapy. B, SDS-score before chemotherapy and QOL-CCC score after chemotherapy. C, SDS score after chemotherapy and QOL-CCC score after chemotherapy. SDS-score and QOL-CCC-score are negatively correlated in all three conditions. 
Besides hematological toxicity, nausea/vomiting and fatigue commonly occurred in both groups. A total of $39(81.3 \%)$ patients in the depression group vs. $53(68 \%)$ in the non-depression group experienced nausea/vomiting, which is a significant difference $(P=0.034)$. Likewise, patients with depression showed a higher incidence of fatigue than those without depression $(56.3 \%$ vs. $48.7 \%, P=0.048)$ (Table 4$)$.

A linear regression analysis confirmed above results, showing no significant difference between SDS score and treatment response or hematological toxicity, but a correlation between SDS score and some non-hematological side effects, including nau- sea/vomiting and fatigue (Figure 4).

\section{Survival}

After chemotherapy, patients with depression had a median progress free survival (PFS) of 114.5 days, and it was 178.5 days for non-depressed patients, showing a difference without statistical significance $(P=0.114)$. However, in one year follow-up, patients without depression had a significantly higher overall survival (OS) rate $(26.96 \%)$ and longer median survival time (279 days) compared with depressed patients who had an OS rate of $14.58 \%$ and a median survival time of 189 days $(P=0.009)$ (Figure 5).
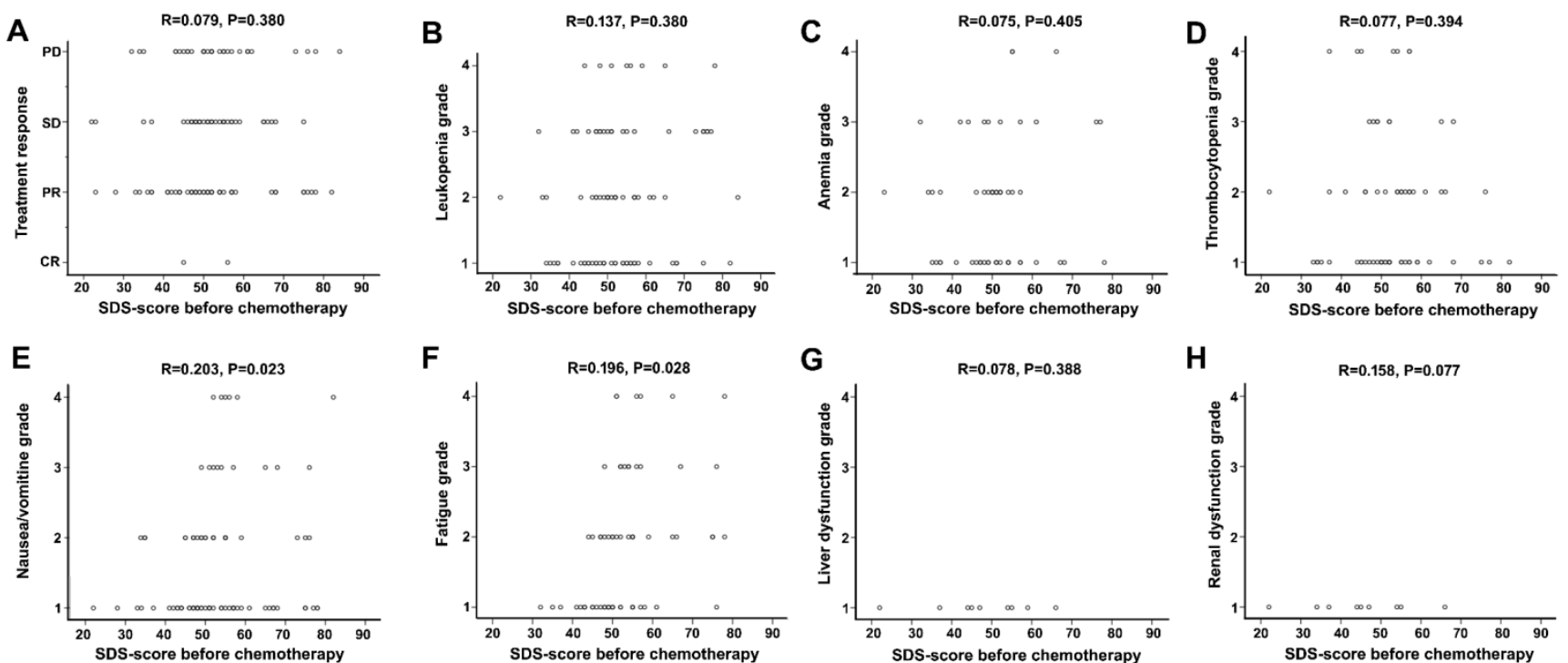

Figure 4. Correlation analysis between depression score and treatment response and toxicity. No correlation was observed between SDS-score and treatment response (A). No negative or positive relation was observed between SDS-score and hematological toxicity (B, C, D). Slight positive relation existed between depression score and incidence of nausea/vomiting, fatigue respectively (E, F). There was no association between depression score and liver dysfunction, renal dysfunction respectively $(G, H)$.
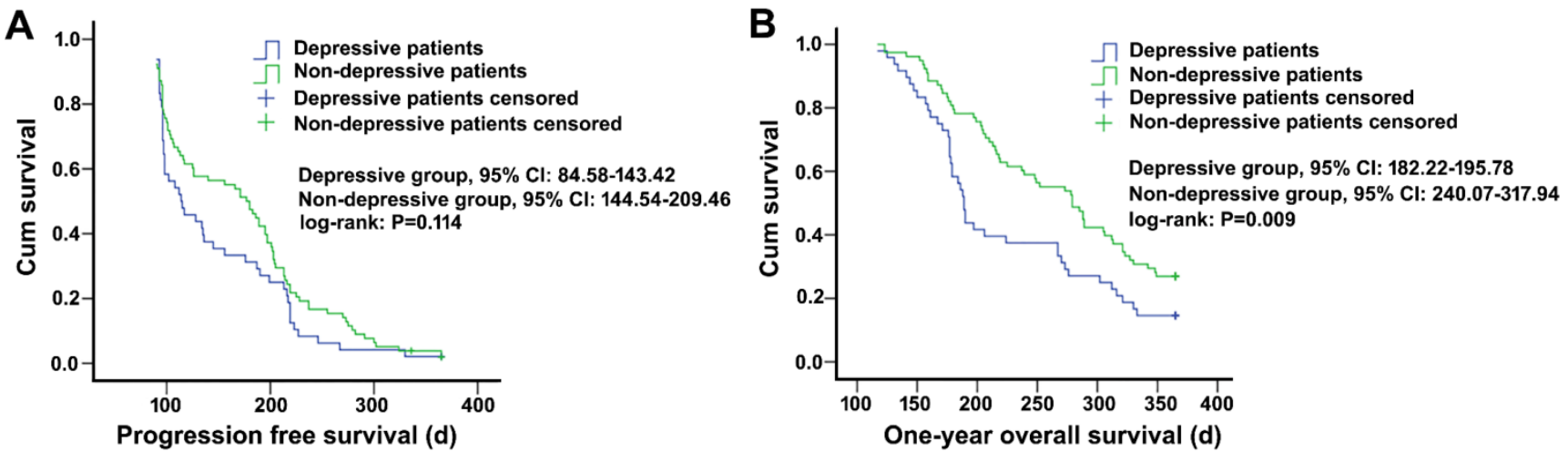

Figure 5. Survival analysis of non-small cell lung cancer patients with and without depression. A, progression-free survival curve, log-rank level of compared factors, $P=0.114$. B, 1-year survival curve, log-rank level of compared factors, $P=0.009$. 
Table 4. Adverse effects of chemotherapy in patients with and without depression

\begin{tabular}{|c|c|c|c|c|c|c|}
\hline \multirow[b]{2}{*}{ Adverse Effects } & \multicolumn{3}{|c|}{ Depression $(n=48)$} & \multicolumn{3}{|c|}{ Non-depression $(n=78)$} \\
\hline & Overall incidence & NCI-CTC grade III & $\begin{array}{l}\text { NCI-CTC grade } \\
\text { IV }\end{array}$ & Overall incidence & NCI-CTC grade III & $\begin{array}{l}\text { NCI-CTC grade } \\
\text { IV }\end{array}$ \\
\hline Leucopenia & $37(77.1 \%)$ & $10(20.8 \%)$ & $5(10.4 \%)$ & $56(71.8 \%)$ & $12(15.4 \%)$ & $3(3.9 \%)$ \\
\hline Anemia & $18(37.8 \%)$ & $5(8.3 \%)$ & $2(6.3 \%)$ & $40(51.3 \%)$ & $6(7.7 \%)$ & 0 \\
\hline Thrombocytopenia & $28(58.3 \%)$ & $3(6.3 \%)$ & $4(8.3 \%)$ & $37(47.4 \%)$ & $5(6.4 \%)$ & $3(3.9 \%)$ \\
\hline Nausea/vomiting & $39(81.3 \%)$ & $5(10.4 \%)$ & $5(10.4 \%)$ & $53(68 \%)^{a}$ & $4(5.1 \%)$ & $1(1.3 \%)$ \\
\hline Fatigue & $27(56.3 \%)$ & $7(14.6 \%)$ & $4(8.3 \%)$ & $38(48.7 \%)^{b}$ & $3(3.9 \%)$ & $2(2.6 \%)$ \\
\hline Liver dysfunction & $4(8.3 \%)$ & 0 & 0 & $5(6.4 \%)$ & 0 & 0 \\
\hline Renal dysfunction & $3(6.3 \%)$ & 0 & 0 & $5(6.4 \%)$ & 0 & 0 \\
\hline
\end{tabular}

Depression versus non-depression: $\mathrm{a}, P=0.034 ; \mathrm{b}, P=0.048$

\section{Discussion}

In the present cross-sectional study, quality of life, progression of disease, adverse effects and survival rates were examined in 48 NSCLC patients with depression and in 78 patients without depression at baseline and during chemotherapy cycles. It was hypothesized that patients with depression would show worse quality of life scores than patients without depression and would also report a decline in quality of life from pre- to post- chemotherapy. This effect was found when patients with depression showed significant decline in the health-related quality of life scales relative to non-depression group (scores: $94.96 \pm 18.14$ vs. $113.58 \pm 14.64, \mathrm{P}<0.01)$. Existing data have shown a negative impact of depression on tumor-related symptoms, QOL, and progression of disease in cancer patients [14, 37-39], confirming our findings. Chemotherapy of the DC regimen recommended in the palliative treatment of advanced lung cancer has shown improvement in survival benefits and QOL [40-42]. Additionally, several other trials provide evidence that chemotherapy offers a survival and QOL benefit in advanced lung cancer patients [43-45]. However, we did not find evidence to support the hypothesis that survival benefit and QOL from the DC regimen therapy was achieved in the NSCLC patients with depression. This negative finding provides a target to improve both health-related quality of life and survival rates in the depressed population with advanced disease and poor prognosis.

Improving quality of life and mood in patients with advanced NSCLC is a major challenge considering the progressive nature of the disease. However, there are many studies in the literature that support the premise that patients with a good health-related quality of life live longer than patients with decreased quality of life or depression [42, 46]. For example, Buccheri followed 133 patients with lung cancer (NSCLC and SCLC) stage I to IV for approximately 2 years. The details of the depression assessment and the cancer treatment were not clearly explained, but patients with higher SDS scores had an increased risk of death compared with the patients with lower scores
[16]. Recently, Arrieta et al reported that depression was associated with decreased HR-QOL, poor adherence to treatment and poor prognosis in patients with advanced NSCLC [47]. These data show that survival might be considered the ultimate end point in NSCLC but depression co-existing with cancer is associated with poor quality of life that puts patients at increased risk of death from cancer. The poor quality of life and decreased survival observed in our study of patients with depression show the negative impact that depression might have on the positive effect of chemotherapy with DC regimen on the QOL.

There is accumulating evidence for an association between depression and reduction in treatment compliance and worse survival in cancer patients [11, 12]. Of several prospective studies focusing on lung cancer patients [16-18], one found a statistically significant association between higher depression scores and an increased risk of mortality from lung cancer [16]. Following palliative care, however, Temel et al showed improvement in quality of life and depression that accounted for the survival benefit in NSCLC patients. Our study hypothesized that the reported benefit of chemotherapy of DC regimen would provide a positive response on depression in NSCLC patients. The data showed that there was no significant difference in the objective response between lung cancer patients with depression and those without depression. In fact, the depression score was similar at baseline and after chemotherapy. Our data suggest that the negative impact of depression might be occurring early in NSCLC cases, and potential mechanisms for the association between depression and survival should be explored in future research at the time of therapy and frequently during follow up.

Several randomized control trials using the chemotherapy DC regimen to treat advanced NSCLC showed that leucopenia, anemia and thrombocytopenia were the most common toxic adverse reactions and non-hematologic toxicities included nausea/emesis and fatigue [48-50]. Similar results were found in our study where the DC regimen proved efficacious with acceptable hematologic toxicities. As a major chemotherapy in patients with newly diag- 
nosed NSCLC, the biweekly schedule of DC therapy showed effective antitumor activity with a marked reduction in hematologic toxicity but the occurrence of nonhematologic reactions of nausea/emesis and fatigue were higher in the depression group. This study analysis showed that depression had a positive relationship with nausea/emesis and fatigue. In this case, depression may be induced by a reaction to chemotherapy. Research has shown that adverse reactions caused by chemotherapy are triggered by an automatic nervous system activity that enhance depressive episodes $[51,52]$. They report that the stress of diagnosis and attention to the side effects of chemotherapy being closely related to the nausea/emesis and fatigue occurring in the duration of chemotherapy. Therefore, compared to the non-depression patients, it is safe to conclude that the depression group in our study was more likely to suffer greater reaction to adverse effects of chemotherapy hence the high levels of nausea and fatigue in this group.

A large percentage of patients with newly diagnosed NSCLC are suspected to have stage IV disease. Therefore, the treatment goals are to prolong survival and control disease-related symptoms. Generally, without systematic chemotherapy, patients with advanced NSCLC have shown a median survival of 5-6 months and one year survival rate of less than $10 \%$ [37]. In one study, once the chemotherapy of DC regimen was administered, however, the median PFS was 4.5 months and the survival rate within 1 year was reported at $23 \%$ to $51 \%$ [50]. In our study, the median PFS of the 126 NSCLC patients was 5.4 months and within 1 year, the survival rate was $22 \%$, similar to the results reported in the literature [50]. The group effect showed there was a higher survival rate in the non-depressed group. This demonstrates the poor prognosis conferred by the complication of depression in lung cancer. It appears to be one of the most important prognostic factor for survival in NSCLC. For example, in two meta-analyses aiming to analyze the prognosis of patients with tumors complicated by depression, the results showed a close association between depression, the progression of the cancer and decline in the long-term survival rates $[53,54]$. Depression might result in poor prognosis and reduce survival rates by reducing treatment compliance, increasing toxicity, deteriorating patients' immunity and decreasing patients' QOL $[55,56]$. It is clear the improvement in PFS and OS during chemotherapy are tempered by the complication of depression but further analyses are needed to understand the effect of depression on tumor progression and survival rates.

Our study had several limitations. First, we included a relatively small number of patients with newly diagnosed NSCLC. Second, the use of a self-reported questionnaire on depression and the absence of a structured clinical interview did not allow us to make any causal conclusions between depression and quality of life and survival rates from our cross-sectional correlation study. In addition, our study focused on quality of life during chemotherapy treatment, as a result, it is not clear whether past history of depressive episodes was also a predictor of long-term quality of life in NSCLC patients. Despite these limitations, our study showed that there is strong correlation between Z-SDS scores and HR-QOL scores, presenting a useful screening tool for depression in addition to quality of life assessment. This needs to be confirmed in a larger study.

It would be interesting to determine if there is still a survival reduction from having depression at baseline in patients with newly diagnosed NSCLC. One study suggested that depressed patients might have more aggressive or treatment-resistant tumors which could have a negative impact on their prognosis regardless of the treatment of depression [57].

In conclusion, patients with newly diagnosed NSCLC should be assessed for depression and treated as early as possible to minimize the effects of baseline depression which can have a negative impact on the patient's quality of life, treatment response, adverse effects and survival. Additionally, clinicians should incorporate diagnostic interviews for depressive disorders, include frequent measures of depression, and evaluate coping styles in palliative treatment of the advanced lung cancer patient.

\section{Conflict of Interest}

None declared.

\section{Acknowledgement}

This work was partially supported by National Natural Science Foundation (Grant No. 81274141) and Science and Technology Bureau of Taizhou City for supporting this study (Grant No. TSHF20110212). We thank the nursing staff from the Department of Oncology and Respiratory, the Second Peoples' Hospital of Taizhou City, Yangzhou University.

\section{References}

1. AmericanCancerSociety. Cancer Facts and Figures. Atlanta, GA: American Cancer Society. 2011.

2. [Internet] WorldHealthOrganization. Cancer: fact sheet no. 297. http://www.who.int/mediacentre/factsheets/fs297/en

3. She J, Yang P, Hong Q, Bai C. Lung cancer in China: challenges and interventions. Chest. 2013; 143: 1117-26.

4. Ramalingam S, Belani C. Systemic chemotherapy for advanced non-small cell lung cancer: recent advances and future directions. Oncologist. 2008; $13 \mathrm{Suppl}$ 1: 5-13.

5. Yang P, Allen MS, Aubry MC, Wampfler JA, Marks RS, Edell ES, et al. Clinical features of 5,628 primary lung cancer patients: experience at Mayo Clinic from 1997 to 2003. Chest. 2005; 128: 452-62. 
6. Amarasena IU, Walters JA, Wood-Baker $\mathrm{R}$, Fong $\mathrm{K}$. Platinum versus non-platinum chemotherapy regimens for small cell lung cancer. Cochrane Database Syst Rev. 2008;: CD006849.

7. Kentepozidis N, Kotsakis A, Soultati A, Agelaki S, Christophylakis C, Agelidou M, et al. Docetaxel plus cisplatin and bevacizumab for untreated patients with advanced/metastatic non-squamous non-small-cell lung cancer: a multicenter phase II study of the Hellenic Oncology Research Group. Cancer Chemother Pharmacol. 2013; 71: 605-12.

8. Le Chevalier T, Monnier A, Douillard JY, Ruffie P, Sun XS, Belli L, et al. Docetaxel (Taxotere) plus cisplatin: an active and well-tolerated combination in patients with advanced non-small cell lung cancer. Eur J Cancer. 1998; 34: 2032-6.

9. Mattson K, Saarinen A, Jekunen A. Combination treatment with docetaxel (Taxotere) and platinum compounds for non-small cell lung cancer. Semin Oncol. 1997; 24: S14-5-S-8.

10. Weiss J, Eaby B, Stevenson J, Kucharczuk J, Cooper J, Kaiser L, et al. Adjuvant cisplatin and docetaxel for non-small cell lung cancer: the Hospital of the University of Pennsylvania experience. J Thorac Oncol. 2010; 5: 667-72.

11. Irwin MR. Depression and insomnia in cancer: prevalence, risk factors, and effects on cancer outcomes. Curr Psychiatry Rep. 2013; 15: 404.

12. Mitchell AJ, Chan $M$, Bhatti $\mathrm{H}$, Halton M, Grassi L, Johansen $\mathrm{C}$, et al. Prevalence of depression, anxiety, and adjustment disorder in oncological, haematological, and palliative-care settings: a meta-analysis of 94 interview-based studies. Lancet Oncol. 2011; 12:160-74.

13. Massie MJ. Prevalence of depression in patients with cancer. J Natl Cancer Inst Monogr. 2004: 57-71

14. Maneeton B, Maneeton N, Reungyos J, Intaprasert S, Leelarphat S, Thongprasert S. Prevalence and relationship between major depressive disorder and lung cancer: a cross-sectional study. Onco Targets Ther. 2014; 7: $815-21$

15. Akechi T, Okamura $\mathrm{H}$, Okuyama $\mathrm{T}$, Furukawa TA, Nishiwaki $\mathrm{Y}$, Uchitomi $\mathrm{Y}$. Psychosocial factors and survival after diagnosis of inoperable non-small cell lung cancer. Psychooncology. 2009; 18: 23-9.

16. Buccheri G. Depressive reactions to lung cancer are common and often followed by a poor outcome. Eur Respir J. 1998; 11: 173-8.

17. Faller H, Bulzebruck H, Drings P, Lang H. Coping, distress, and survival among patients with lung cancer. Arch Gen Psychiatry. 1999; 56: 756-62.

18. Faller $\mathrm{H}$, Schmidt M. Prognostic value of depressive coping and depression in survival of lung cancer patients. Psychooncology. 2004; 13: 359-63.

19. Nakaya N, Saito-Nakaya K, Akizuki N, Yoshikawa E, Kobayakawa M, Fujimori M, et al. Depression and survival in patients with non-small cell lung cancer after curative resection: a preliminary study. Cancer Sci. 2006; 97: 199-205

20. Pirl WF, Greer JA, Traeger L, Jackson V, Lennes IT, Gallagher ER, et al. Depression and survival in metastatic non-small-cell lung cancer: effects of early palliative care. J Clin Oncol. 2012; 30: 1310-5.

21. Pirl WF, Temel JS, Billings A, Dahlin C, Jackson V, Prigerson HG, et al. Depression after diagnosis of advanced non-small cell lung cancer and survival: a pilot study. Psychosomatics. 2008; 49: 218-24.

22. Ganz PA, Lee JJ, Siau J. Quality of life assessment. An independent prognostic variable for survival in lung cancer. Cancer. 1991; 67: 3131-5.

23. Sloan JA, Zhao X, Novotny PJ, Wampfler J, Garces Y, Clark MM, et al Relationship between deficits in overall quality of life and non-small-cell lung cancer survival. J Clin Oncol. 2012; 30: 1498-504.

24. DiMatteo MR, Lepper HS, Croghan TW. Depression is a risk factor for noncompliance with medical treatment: meta-analysis of the effects of anxiety and depression on patient adherence. Arch Intern Med. 2000; 160: 2101-7.

25. Luo J, Sun Y, Zhou S. Development of quality of life questionnaire for Chinese cancer patients receiving chemobiotherapy. Zhonghua Zhong Liu Za Zhi. 1997; 19: 437-41.

26. Yan H, Sellick K. Symptoms, psychological distress, social support, and quality of life of Chinese patients newly diagnosed with gastrointestinal cancer. Cancer Nurs. 2004; 27: 389-99.

27. Yan H, Sellick K. Quality of life of Chinese patients newly diagnosed with gastrointestinal cancer: a longitudinal study. Int J Nurs Stud. 2004; 41: 309-19.

28. Zhao H, Kanda K. Translation and validation of the standard Chinese version of the EORTC QLQ-C30. Qual Life Res. 2000; 9: 129-37.

29. Zhao H, Kanda K. Testing psychometric properties of the standard Chinese version of the European Organization for Research and Treatment of Cancer Quality of Life Core Questionnaire 30 (EORTC QLQ-C30). J Epidemiol. 2004; 14: 193-203.

30. Zung WW. Depression in the normal aged. Psychosomatics. 1967; 8: 287-92.

31. Zung WW. Factors influencing the self-rating depression scale. Arch Gen Psychiatry. 1967; 16: 543-7

32. Dugan W, McDonald MV, Passik SD, Rosenfeld BD, Theobald D, Edgerton S. Use of the Zung Self-Rating Depression Scale in cancer patients: feasibility as a screening tool. Psychooncology. 1998; 7: 483-93.

33. Passik SD, Lundberg JC, Rosenfeld B, Kirsh KL, Donaghy K, Theobald D, et al. Factor analysis of the Zung Self-Rating Depression Scale in a large ambulatory oncology sample. Psychosomatics. 2000; 41: 121-7.

34. Therasse P, Arbuck SG, Eisenhauer EA, Wanders J, Kaplan RS, Rubinstein L, et al. New guidelines to evaluate the response to treatment in solid tumors. European Organization for Research and Treatment of Cancer, National Cancer Institute of the United States, National Cancer Institute of Canada. J Natl Cancer Inst. 2000; 92: 205-16.
35. Arbuck SG, Ivy SP, Setser Aea. The Revised Common Toxicity Criteria, Version 2.0. CTEP Website http://ctepinfonihgov. 1999.

36. Goel MK, Khanna P, Kishore J. Understanding survival analysis: Kaplan-Meier estimate. Int J Ayurveda Res. 2010; 1: 274-8.

37. Pinquart M, Koch A, Eberhardt B, Brix C, Wedding U, Rohrig B. Associations of functional status and depressive symptoms with health-related quality of life in cancer patients. Oual Life Res. 2006; 15: 1565-70.

38. Smith EM, Gomm SA, Dickens CM. Assessing the independent contribution to quality of life from anxiety and depression in patients with advanced cancer. Palliat Med. 2003; 17: 509-13.

39. Wedding U, Koch A, Rohrig B, Pientka L, Sauer H, Hoffken K, et al. Depression and functional impairment independently contribute to decreased quality of life in cancer patients prior to chemotherapy. Acta Oncol. 2008; 47: 56-62.

40. Belani CP, Pereira JR, von Pawel J, Pluzanska A, Gorbounova V, Kaukel E, et al. Effect of chemotherapy for advanced non-small cell lung cancer on patients' quality of life. A randomized controlled trial. Lung Cancer. 2006; 53: 231-9.

41. Socinski MA, Evans T, Gettinger S, Hensing TA, Sequist LV, Ireland B, et al. Treatment of stage IV non-small cell lung cancer: Diagnosis and management of lung cancer, 3rd ed: American College of Chest Physicians evidence-based clinical practice guidelines. Chest. 2013; 143: e341S-68S.

42. Temel JS, Greer JA, Muzikansky A, Gallagher ER, Admane S, Jackson VA, et al. Early palliative care for patients with metastatic non-small-cell lung cancer. N Engl J Med. 2010; 363: 733-42.

43. Ciuleanu T, Brodowicz T, Zielinski C, Kim JH, Krzakowski M, Laack E, et al. Maintenance pemetrexed plus best supportive care versus placebo plus best supportive care for non-small-cell lung cancer: a randomised, double-blind, phase 3 study. Lancet. 2009; 374: 1432-40.

44. O'Brien ME, Ciuleanu TE, Tsekov H, Shparyk Y, Cucevia B, Juhasz G, et al. Phase III trial comparing supportive care alone with supportive care with oral topotecan in patients with relapsed small-cell lung cancer. J Clin Oncol. 2006; 24. 5441-7.

45. Shepherd FA, Dancey J, Ramlau R, Mattson K, Gralla R, O'Rourke M, et al. Prospective randomized trial of docetaxel versus best supportive care in patients with non-small-cell lung cancer previously treated with platinum-based chemotherapy. J Clin Oncol. 2000; 18: 2095-103.

46. Lithoxopoulou H, Zarogoulidis K, Bostantzopoulou S, Eleftheriadou E, Zarogoulidis $\mathrm{P}$, Huang $\mathrm{H}$, et al. Monitoring changes in quality of life in patients with lung cancer by using specialised questionnaires: implications for clinical practice. Support Care Cancer. 2014; 22: 2177-83

47. Arrieta O, Angulo LP, Nunez-Valencia C, Dorantes-Gallareta Y, Macedo EO, Martinez-Lopez D, et al. Association of depression and anxiety on quality of life, treatment adherence, and prognosis in patients with advanced non-small cell lung cancer. Ann Surg Oncol. 2013; 20: 1941-8.

48. Cho SH, Go SI, Lee GW, Kang JH, Kim HG, Kim SH, et al. Phase II study of a biweekly schedule of docetaxel and cisplatin in patients with metastatic non-small cell lung cancer. Lung Cancer. 2010; 69: 94-8.

49. Haura EB. Treatment of advanced non-small-cell lung cancer: a review of current randomized clinical trials and an examination of emerging therapies. Cancer Control. 2001; 8: 326-36

50. Shen G, Bian G, Yu H, Gao M, Kang D, Hu S. Comparison between cisplatin plus vinorelbine and cisplatin plus docetaxel in the treatment of advanced non-small-cell lung cancer: A meta-analysis of randomized controlled trials. Mol Clin Oncol. 2014; 2: 146-50.

51. Zachariae $R$, Paulsen $K$, Mehlsen $M$, Jensen $A B$, Johansson $A$, von der Maase H. Chemotherapy-induced nausea, vomiting, and fatigue--the role of individual differences related to sensory perception and autonomic reactivity. Psychother Psychosom. 2007; 76: 376-84

52. Zachariae $R$, Paulsen $K$, Mehlsen $M$, Jensen $A B$, Johansson $A$, von der Maase $H$. Anticipatory nausea: the role of individual differences related to sensory perception and autonomic reactivity. Ann Behav Med. 2007; 33: 69-79.

53. Pinquart M, Duberstein PR. Depression and cancer mortality: a meta-analysis. Psychol Med. 2010; 40: 1797-810.

54. Riblet N, Larson R, Watts BV, Holtzheimer P. Reevaluating the role of antidepressants in cancer-related depression: a systematic review and meta-analysis. Gen Hosp Psychiatry. 2014; 36: 466-73.

55. Greer JA, Pirl WF, Park ER, Lynch TJ, Temel JS. Behavioral and psychological predictors of chemotherapy adherence in patients with advanced non-small cell lung cancer. J Psychosom Res. 2008; 65: 549-52.

56. Rabin EG, Heldt E, Hirakata VN, Bittelbrunn AC, Chachamovich E, Fleck MP. Depression and perceptions of quality of life of breast cancer survivors and their male partners. Oncol Nurs Forum. 2009; 36: E153-8.

57. Pirl WF, Traeger L, Greer JA, Bemis H, Gallagher E, Lennes I, et al. Tumor epidermal growth factor receptor genotype and depression in stage IV non-small cell lung cancer. Oncologist. 2011; 16: 1299-306. 